\title{
Roles of Thrombospondin-1 and -2 in Regulating Corneal and Iris Angiogenesis
}

\section{Citation}

Cursiefen, Claus, Sharmila Masli, Tat Fong Ng, M. Reza Dana, Paul Bornstein, Jack Lawler, and J. Wayne Streilein. 2004. "Roles of Thrombospondin-1 and -2 in Regulating Corneal and Iris Angiogenesis." Investigative Opthalmology \& Visual Science 45 (4) (April 1): 1117. doi:10.1167/ iovs.03-0940.

\section{Published Version}

10.1167/iovs.03-0940

\section{Permanent link}

http://nrs.harvard.edu/urn-3:HUL.InstRepos:34388129

\section{Terms of Use}

This article was downloaded from Harvard University's DASH repository, and is made available under the terms and conditions applicable to Other Posted Material, as set forth at http:// nrs.harvard.edu/urn-3:HUL.InstRepos:dash.current.terms-of-use\#LAA

\section{Share Your Story}

The Harvard community has made this article openly available.

Please share how this access benefits you. Submit a story.

\section{Accessibility}




\title{
Roles of Thrombospondin-1 and -2 in Regulating Corneal and Iris Angiogenesis
}

\author{
Claus Cursiefen, ${ }^{1}$ Sharmila Masli, ${ }^{1}$ Tat Fong $\mathrm{Ng},{ }^{1}$ M. Reza Dana,${ }^{1}$ Paul Bornstein, ${ }^{2}$ \\ Jack Lawler, ${ }^{3}$ and J. Wayne Streilein ${ }^{1}$
}

PurPose. Thrombospondin (TSP)-1 and -2 are important antiangiogenic factors thought to be involved in maintaining corneal avascularity (angiogenic privilege). This study was undertaken to investigate whether deficiencies of these factors altered developmental and inflammation-induced angiogenesis in the cornea and developmental angiogenesis of the iris of mice.

Methods. Expression of TSP-1 and -2 mRNA and protein was assayed in cornea and iris stroma by RT-PCR and Western blot. Corneas and irides of TSP- $1^{-1-}$, TSP- $2^{-1-}$, and TSP- $1,2^{-{ }^{-}}$mice aged 2, 3, and 6 months, and wild-type control mice, were analyzed for spontaneous angiogenesis biomicroscopically, histologically, and with CD31 immunohistochemistry. The mouse model of suture-induced, inflammatory corneal neovascularization was used to evaluate the lack of TSP-1,2 and both TSPs on induced-corneal angiogenesis. Seven days after intrastromal placement of three 11-0 sutures, vascularized areas were analyzed morphometrically on CD31-stained corneal flatmounts.

REsults. Corneas and irises from normal mouse eyes constitutively expressed TSP-1 and - 2 mRNAs and proteins. Corneas of TSP- $1^{-{ }^{-}},-2^{-/-}$, and $-1,2^{-/-}$mice displayed no evidence of spontaneous developmental-postnatal angiogenesis, although irises of these mice contained significantly increased iris vessel density compared with wild-type animals $(P<0.01)$. One week after suturing, corneas of all $\mathrm{TSP}^{-/-}$mice had significantly greater corneal angiogenesis than those of control mice $(P<0.05)$. TSP- $1^{-1-}$ had a significantly greater effect on induced corneal neovascularization than did TSP-2 $2^{-/-}$, with the opposite being the case in developmental iris angiogenesis $(P<0.01)$.

Conclusions. Corneal avascularity during development is redundantly regulated, shown by the fact that lack of the antiangiogenic factors TSP-1 and/or -2 resulted in no spontaneous corneal angiogenesis. By contrast, TSP-1, more than TSP-2,

From ${ }^{1}$ The Schepens Eye Research Institute, Department of Ophthalmology, Harvard Medical School, Boston Massachusetts; the ${ }^{2}$ Department of Biochemistry, Department of Medicine, University of Washington, Seattle, Washington; and the ${ }^{3}$ Department of Pathology, Beth Israel Deaconess Medical Center, Research North, Boston, Massachusetts.

Supported by Deutsche Forschungsgemeinschaft Grants $\mathrm{Cu} 47 /$ 1-1 and $\mathrm{Cu}$ 47/1-2 (CC); National Eye Institute Grants EY10765 and EY12963; National Heart, Lung, and Blood Institute Grant HL68003; National Institute of Arthritis and Musculoskeletal and Skin Diseases Grant AR45418; and National Cancer Institute Grant CA92644.

Submitted for publication August 27, 2003; revised December 3, 2003, and January 8, 2004; accepted January 9, 2004.

Disclosure: C. Cursiefen, None; S. Masli, None; T.F. Ng, None; M.R. Dana, None; P. Bornstein, None; J. Lawler, None; J.W. Streilein, None

The publication costs of this article were defrayed in part by page charge payment. This article must therefore be marked "advertisement" in accordance with 18 U.S.C. $\$ 1734$ solely to indicate this fact

Corresponding author: J. Wayne Streilein, The Schepens Eye Research Institute, Department of Ophthalmology, Harvard Medical School, 20 Staniford Street, Boston, MA 02114;

waynes@vision.eri.harvard.edu. helps to suppress inflammation-induced corneal angiogenesis postnatally, implying that angiogenic privilege in the cornea is actively maintained. (Invest Ophthalmol Vis Sci. 2004;45: 1117-1124) DOI:10.1167/iovs.03-0940

$\mathbf{R}_{\mathrm{i}}^{\mathrm{c}}$ egulation of angiogenesis in the eye, especially the cornea, is important in maintaining the integrity of the visual axis. The normal cornea is devoid of both blood and lymph vessels, except at the limbus. When challenged by certain types of injury and inflammation, the cornea is prevented from responding with angiogenesis from preexisting limbal blood vessels. This failure has given rise to the term "angiogenic privilege" in analogy, with the term "immune privilege," which denotes the inherent resistance of the cornea to display inflammation. ${ }^{1,2}$ As is the case with immune privilege, angiogenic privilege is not absolute, and there are many corneal conditions and surgical manipulations that induce blood and lymph vessels to invade the stroma from the limbus. ${ }^{3}$

The mechanisms underlying angiogenic privilege are poorly understood, ${ }^{4}$ although it is thought that antiangiogenic factors present in the cornea and in aqueous humor are important. ${ }^{1,5}$ Heparan sulfate proteoglycans in aqueous humor may contribute to corneal avascularity by binding and sequestering angiogenic growth factors such as vascular endothelial growth factor (VEGF) and fibroblast growth factor (FGF). ${ }^{5}$ The cornea itself is believed to produce and contain numerous antiangiogenic factors, including the thrombospondins (TSPs), ${ }^{6}$ pigment epithelial-derived factor (PEDF), ${ }^{7}$ tissue inhibitor of matrix metalloproteinase (TIMP), ${ }^{8}$ endostatin (precursor:collagen type XVIII), ${ }^{9}$ angiostatin (precursor:plasminogen) (Hernandez-Quintela E, et al. IOVS 1999; 40:ARVO Abstract 521), and angiopoietin-like factor CDT6. ${ }^{10}$ The plethora of factors capable of inhibiting angiogenesis in the cornea and aqueous humor suggests that physiologic control of angiogenesis in the cornea is redundantly regulated. The experimental results reported herein were designed to test this novel concept of redundant organization of corneal avascularity.

Thrombospondins are generated from a family of five genes encoding glycoproteins that regulate multiple extracellular matrix functions. Within this family, TSP-1 and -2 constitute a subfamily with strong antiangiogenic effects (Refs. 11-13). TSP-1, which can bind to latent transforming growth factor (TGF)- $\beta$ and promote its activation, is thought to inhibit angiogenesis through direct effects on endothelial cell migration and survival (e.g., by inducing vascular endothelial cell apoptosis through its binding to $\mathrm{CD} 36)^{14}$ as well as through indirect effects on growth factor mobilization (e.g., by binding heparan sulfate proteoglycans). ${ }^{11,12}$ This has yet to be shown to be true for corneal and iris angiogenesis. TSP-2, which lacks a TGF $\beta$ binding site, is also a multifunctional protein with antiangiogenic properties that binds to multiple receptors and is capable of inhibiting cell-cycle progression in endothelial cells in the absence of apoptosis (for review, see Ref. 13). Although the exact mechanisms by which TSP-1 and -2 achieve their antiangiogenic effects are not yet fully understood, both TSP-1 and -2 have been shown to inhibit bFGF-induced corneal neovascularization $(\mathrm{CNV}){ }^{15,16}$ Evidence suggests that TSP may be ex- 
pressed in the normal cornea. Light-microscopic immunoreactivity for TSP-1 was observed in human and bovine corneal endothelium, epithelial basement membrane, and posterior Descemet's membrane. ${ }^{6}$ Expression of TSP-1 and -2 in the mouse cornea and iris have yet to be studied.

To test the hypothesis that corneal avascularity is redundantly regulated, we examined the corneas of TSP-1 $1^{-1-},-2^{-1-}$, and $-1,2$ double-deficient mice for evidence of spontaneous and induced CNV. To our knowledge, this is the first study to examine the effect of eliminating only one or two of the many antiangiogenic factors believed to regulate angiogenesis in the cornea in vivo, with respect to developmental and induced $\mathrm{CNV}$. For comparison, the degree of vascularization in a normally vascularized ocular tissue, the iris, was also examined. Our results indicate that spontaneous corneal avascularity is redundantly regulated, and that, by contrast, induced corneal vascularity and developmental iris vascularity are primarily dependent on the actions of TSP-1 and -2.

\section{Methods}

\section{TSP $^{-/-}$Mice and Anesthesia}

Mice deficient in TSP-1, -2, and both TSP-1 and -2 were created as described before. ${ }^{17-19}$ Briefly, in TSP-1 ${ }^{-/-}$mice, the region of genomic DNA containing exon 2, intron 3, and exon 3 was removed and replaced with the neomycin-resistant gene driven by the phosphoglycerate kinase promotor. ${ }^{17}$ TSP- $2^{-\prime-}$ mice were generated by targeted disruption of the Thbs 2 gene in embryonic stem cells, which deleted exons 2 and 3 (including the translation site). ${ }^{20}$ TSP- $1,2^{-1-}$ mice were generated as previously described. ${ }^{18}$ All mice were on an FVB background. Equal numbers of male and female mice were analyzed. All animals used for suture-induced CNV experiments were between 8 and 12 weeks of age and were treated in accordance with the ARVO Statement for the Use of Animals in Ophthalmic and Vision Research. Each mouse was anesthetized before all surgical procedures by intraperitoneal injection of a mixture of $4 \mathrm{mg}$ ketamine and $0.1 \mathrm{mg}$ xylazine.

\section{Clinical and Histologic Evaluation of Cornea and Iris in TSP $^{-/-}$Mice}

At the ages of 2, 3, and 6 months, mice deficient in TSP-1, -2, or both TSP-1 and -2 were examined biomicroscopically while under anesthesia to detect corneal blood vessels. At least eight eyes (of four mice) were examined per time point. Subsequently, mice were killed and both eyes enucleated. The eyes were immediately fixed in $10 \%$ buffered formalin and later embedded in plastic. Five-micrometer pupiloptic disc sections, stained with hematoxylin and eosin, were then evaluated microscopically for corneal diseases and corneal blood vessels (at least 10 pupil-optic disc central sections per eye). In addition, corneal wholemounts of TSP-deficient mice (TSP-1, -2, or both TSP-1 and -2) at the age of 6 months were stained with antibodies to plateletendothelial cell adhesion molecule (PECAM 1/CD31; Santa Cruz Biotechnology, Santa Cruz, CA; 1:100), as described later, and analyzed for blood vessels extending beyond the limbus by immunofluorescence microscope (Axiophot light microscope; Carl Zeiss Meditec, Dublin, CA).

\section{Quantification of Iris Vascular Density in $\mathrm{TSP}^{-/-}$ and Wild-Type Mice}

The number and density of iris stromal vessels was evaluated in TSPdeficient mice (TSP-1, -2, or both TSP-1 and -2) as follows: central, pupil-optic disc sections of eyes of mice (2,3, or 6 months of age) were stained with hematoxylin and eosin, as described earlier, and analyzed by light microscopy (Axiophot light microscope; Carl Zeiss Meditec). Representative pupil-optic disc sections with similar iris diameter were analyzed, and all clearly identifiable vessel cross-sections were counted by a masked observer, who had no knowledge of the genotype of the tissues. At least eight eyes (of four mice) were examined per time point.

\section{Induction and Quantification of Corneal Angiogenesis in CD31-Stained Corneal Flatmounts}

To induce $\mathrm{CNV}$, the established model of suture-induced inflammatory CNV was applied, as described previously with slight modifications, on TSP- $1^{-1-},-2^{-/-}$, and $-1,2^{-/-}$mice and their wild-type FVB background strain. ${ }^{20}$ Briefly, a 2-mm corneal trephine was gently placed on the central cornea of anesthetized mice solely to mark the central corneal area. Three 11-0 sutures were then placed intrastromally with two stromal incursions extending over $120^{\circ}$ of corneal circumference each. The outer point of suture placement was chosen as halfway between the limbus and the line outlined by the 2-mm trephine, and the inner suture point was equidistant from the 2-mm trephine line to obtain standardized angiogenic responses. Sutures were left in place for 7 days. Mice were euthanized, the cornea with limbus was then excised, and modified flatmount double-immunohistochemistry was performed as previously described. ${ }^{21}$

Corneal flatmounts were rinsed in PBS, fixed in acetone, rinsed in PBS, blocked in $2 \%$ bovine serum albumin, stained with FITC-conjugated anti-CD31/PECAM- 1 at $4^{\circ} \mathrm{C}$ overnight (1:100; Santa Cruz Biotechnology), washed, blocked, stained with LYVE-1 at $4^{\circ} \mathrm{C}$ overnight (1: 100; a lymphatic endothelium-specific hyaluronic acid receptor; generous gift of David Jackson, Oxford, UK), ${ }^{22}$ washed, blocked, and stained with $\mathrm{Cy} 3$ for 1 hour at room temperature (1:100; Jackson ImmunoResearch Laboratories, West Grove, PA) and analyzed by microscope (Carl Zeiss Meditec; Axiophot). Digital pictures of the flatmounts were taken using an image-analysis system (Spot Image Analysis; Diagnostic Instruments, Sterling Heights, MI). Then, the area covered by $\mathrm{CD} 31^{2+} / \mathrm{LYVE}^{-} 1^{-}$vessels (i.e., blood vessels) ${ }^{3,22}$ was measured morphometrically on these flatmounts using NIH Image software (available by ftp at zippy.nimh.nih.gov/ or at http://rsb.info.nih.gov/ nih-image; developed by Wayne Rasband, National Institutes of Health, Bethesda, MD). The total corneal area was outlined using the innermost vessel of the limbal arcade as the border. The total area of neovascularization was then normalized to the total corneal area, and the percentage of the cornea covered by vessels calculated. Isotype control mice were used as the negative control.

\section{RT-PCR for TSP-1 and -2 in Cornea and Iris Tissue}

RT-PCR was performed as previously described. ${ }^{23}$ Briefly, total RNA was extracted from 20 central corneas and iris tissues immediately after 10 mice were killed (RNAStat-60; Tel-Test Inc., Friendswood, TX). cDNA was synthesized from $5 \mu \mathrm{g}$ RNA with M-MLV reverse transcriptase (Promega, Madison, WI) according to the manufacturer's instructions. The following primers were used for PCR from 5' to $3^{\prime}$ : GAPDH sense, GGTGAAGGTCGGTGTGAACGGA; antisense, TGTTAGTGGGGTCTCGCTCCTG; TSP-1 sense, GTTCGTCGGAAGGATTGTTA; antisense, TCTATTCCAATGGCAACGAG; and TSP-2 sense, CAGAGTACTGGCGTCGGT CA; antisense, ATAAGATCGCAGCCCACATACAG. All primers were designed by Sigma Genosys (Woodlands, TX). PCR was performed under the following conditions: denaturation at $94^{\circ} \mathrm{C}$; annealing at $52.7^{\circ} \mathrm{C}\left(\mathrm{TSP}-1\right.$; TSP-2: $\left.58.7^{\circ} \mathrm{C}\right)$ and extension at $72^{\circ} \mathrm{C}$. After 40 cycles of amplification (AmpliTaq DNA Polymerase; Applied Biosystems, Foster City, CA), PCR products were electrophoresed in $2 \%$ agarose gel and visualized by ethidium bromide staining $(0.5 \mu \mathrm{g} / \mathrm{mL}$ ethidium bromide) for 40 minutes. Photographs of the gel were taken with a high-resolution camera, and the density of the bands was analyzed on the gel using UV-illumination and image-analysis software (Image One; Bio-Rad, Hercules, CA). The expression level of mRNA was standardized by the expression of GAPDH as an internal control. The predicted sizes of PCR products are 733 bp for TSP-1, 649 bp for TSP-2, and $245 \mathrm{bp}$ for GAPDH.

\section{Western Blot for TSP-1 and -2 in Cornea and Iris}

Cell lysates were prepared from 20 corneas and irises excised from 10 wild-type mice in each experiment using lysis buffer (Active Motif Inc., 


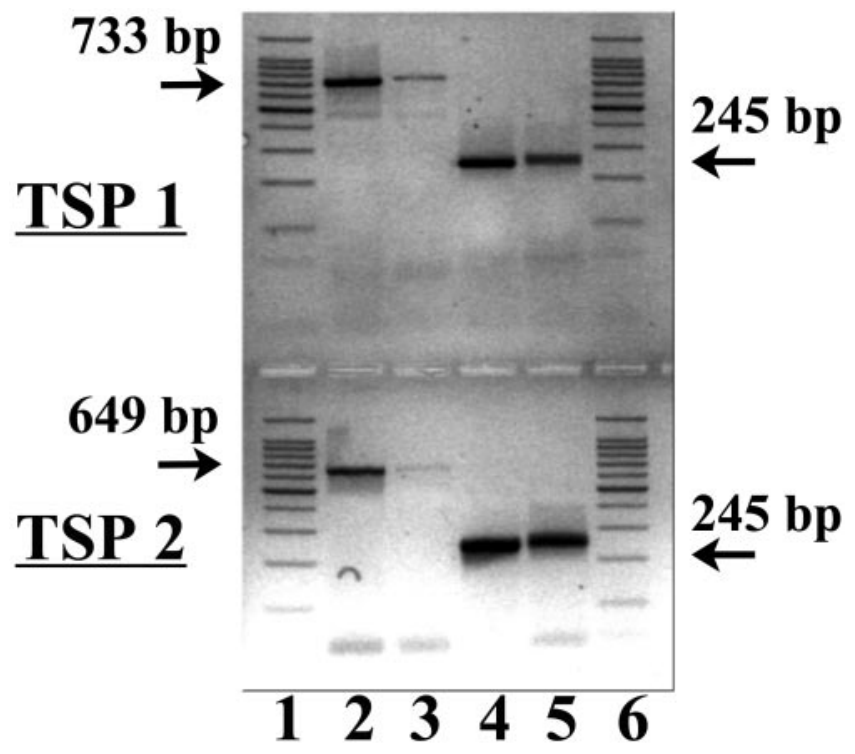

FIGURE 1. Normal cornea and iris transcribed both TSP-1 and -2 . Transcription of TSP-1 (top) and -2 (bottom) in normal cornea (lane 2) and iris (lane 3) of FVB background strain mice (compared with cornea [lane 4] and iris [lane 5] GAPDH expression; lanes 1 and 6 : 100-bp molecular marker). Densitometry showed mean TSP-1 expression to be 2.6 times higher in corneas than in irises and 16.5 times higher for TSP-2; normalized to GAPDH expression.

Carlsbad, CA) according to the manufacturer's instructions. Protein content of lysates were determined using bicinchoninic acid (BCA) protein assay (Pierce, Rockford, IL). Recombinant TSP-2 and -1 protein, purified from thrombin-treated human blood platelets, were used as positive control mice $(1 \mu \mathrm{g})$. Isotype controls were used as negative controls. Equal quantities of protein from lysates $(10 \mu \mathrm{g})$ were subjected to SDS-PAGE in 3\% to $8 \%$ Tris-acetate gradient gel (Invitrogen Inc., Carlsbad, CA) followed by electrophoretic transfer of separated proteins to nitrocellulose membranes (Pierce). Western blot analysis was performed using anti-TSP-1 or - 2 antibodies (BD Biosciences, San Diego, CA). These antibodies were shown to be specific for their designated TSPs on Western blot. Antibodies bound to proteins on the membrane were detected using horseradish peroxidase conjugated secondary antibody (Santa Cruz Biotechnology) and chemiluminescent substrate (ECL detection reagents; Amersham Pharmacia Biotech, Piscataway, NJ) followed by signal detection on autoradiograph film (Biomax; Eastman Kodak, Rochester, NY).

\section{Statistical Analysis}

Statistical significance was analyzed by the Mann-Whitney test. Differences were considered significant at $P<0.05$. Each experiment was performed at least three times with similar results. Graphs were composed on computer (Prism ver. 3.02; GraphPad, San Diego, CA).

\section{RESUlTS}

\section{Expression of TSP-1 and -2 mRNA and Protein in Normal Mouse Cornea and Iris}

Because TSP-1 and -2 are important regulators of developmental iris angiogenesis and induced $\mathrm{CNV}$, we wondered whether the TSP- 1 and -2 genes are transcriptionally active in cornea and iris of normal mice. To examine this point, corneas and irises were obtained from wild-type mice and subjected to semiquantitative RT-PCR analysis to detect relevant mRNA species. As revealed in Figure 1, wild-type mouse corneas displayed mRNA for both TSP-1 and -2, as did wild-type mouse iris. Mean TSP-1 expression was 2.6 times higher in corneas than in irises (normalized to GAPDH expression), and mean TSP-2 expression was 16.5 times higher in corneas than in irises (normalized to GAPDH expression). In addition, there was higher mean TSP-1 expression compared with mean TSP-2 expression (2.6 times more TSP-1 in corneas compared with TSP-2, and 14 times more TSP-1 in irises compared with TSP-2). Thus, cells within the normal iris and cornea have the constitutive potential to generate the antiangiogenic factors, TSP-1 and -2 .

This observation was further confirmed by detection of TSP-1 and -2 proteins in cells extracted from cornea and iris tissue harvested from wild-type mice. Western blot analysis was performed on equal quantities of protein isolated from either tissue as described in the Methods section. Figure 2 shows a representative blot that reveals the presence of TSP-1 and -2 proteins in cornea as well as iris. In line with the mRNA findings, both TSP- 1 and -2 proteins were detectable in cornea and iris tissue (with more TSP-1 and -2 in cornea than in iris tissue).

\section{Influence of Deficiency of TSP-1, -2, or Both TSP-1 and -2, on Developmental and Postnatal Corneal Avascularity}

The fully developed cornea is devoid of blood and lymph vessels unless trauma or inflammation has intervened. To test whether developmental and postnatal corneal avascularity is redundantly regulated by TSPs and other antiangiogenic factors, corneas of TSP-1 $1^{-{ }^{-}},-2^{-/-}$, and $-1,2^{-{ }^{-}}$mice, as well as age-matched corneas from wild-type mice, were evaluated for evidence of spontaneous $\mathrm{CNV}$ at ages 2, 3, and 6 months. By slit lamp examination of hematoxylin-and-eosin-stained serial sections of excised corneas and by analyzing CD31/PECAM 1-stained corneal flatmounts immunohistochemically we found no evidence of intrastromal vessels beyond the limbus in either wild-type or $\mathrm{TSP}^{-1-}$ corneas (Fig. 3). Moreover, by clinical observation, we detected no difference in corneal clarity or limbal architecture between $\mathrm{TSP}^{-/-}$mice and wild-type control animals. Similarly, by histology, we found no gross differences in the anatomy of the corneal epithelium, stroma, or endothelium, comparing knockout mice and control animals. Thus, postnatal corneal avascularity does not appear to require TSP-1 or -2, in that complete absence of TSP-1 and/or -2 had no effect on the expected normal phenotype. This finding suggests that corneal avascularity is redundantly controlled by other antiangiogenic factors, in addition to TSPs.

\section{TSP1-
control Cornea Iris}

Anti-TSP1

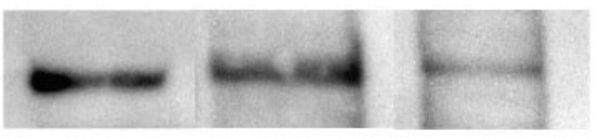

\section{contrö Cornea Iris}

\section{Anti-TSP2}

FigURE 2. Normal cornea and iris expressed both TSP-1 and -2 protein. Note the higher expression of TSP-1 and -2 in cornea than in iris. 


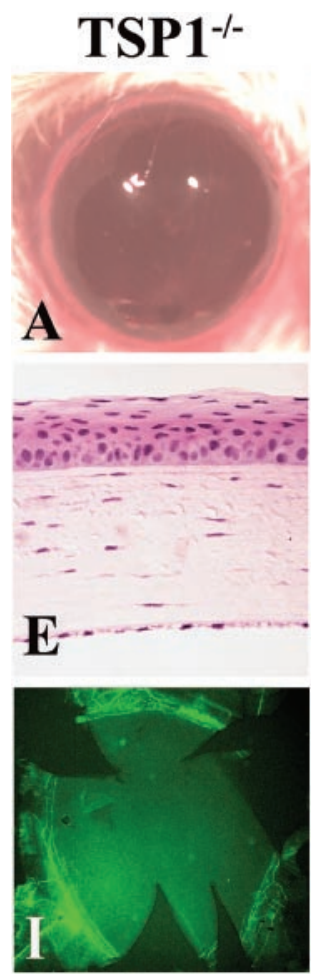

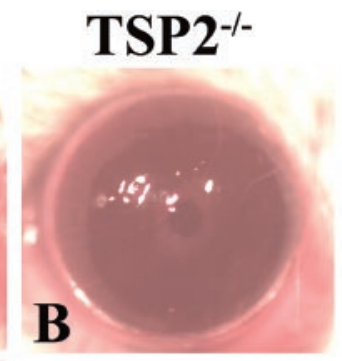
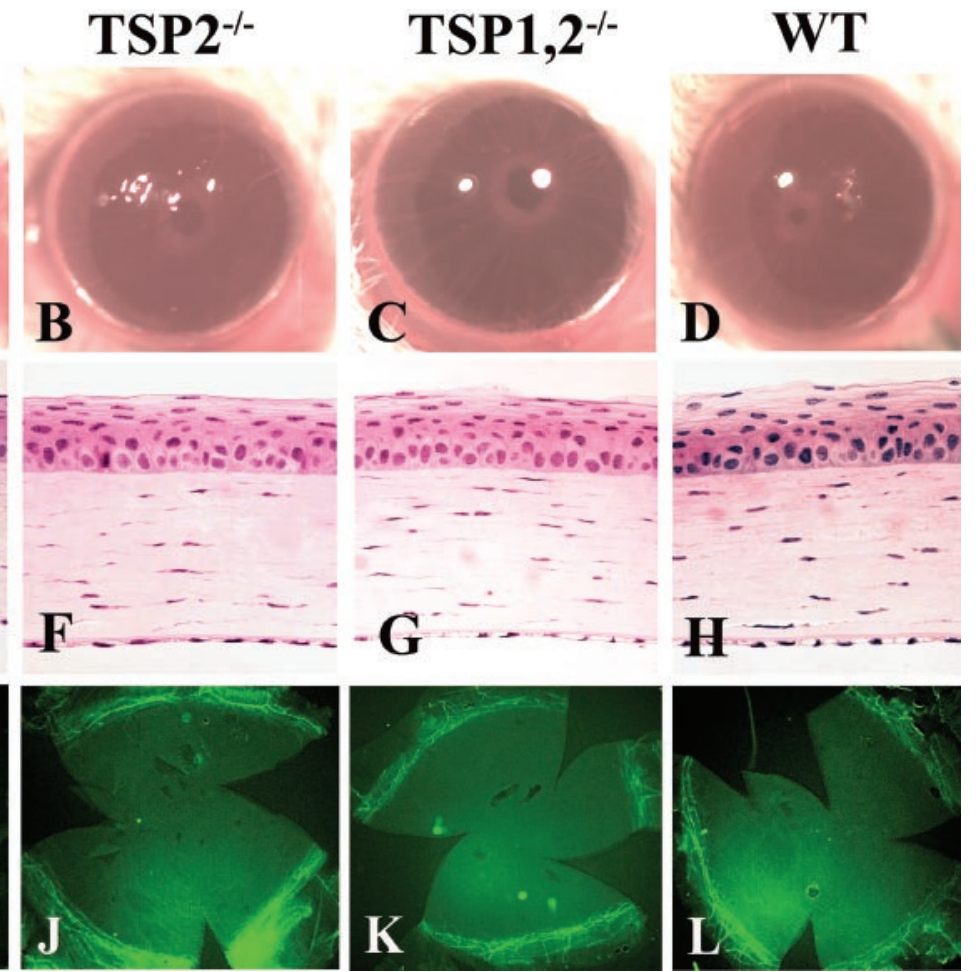

Figure 3. Absence of the antiangiogenic factors TSP-1, -2, or both TSP-1 and -2 did not cause spontaneous corneal angiogenesis. By slit lamp examination (A-D), histologic examination $(\mathbf{E}-\mathbf{H}$; hematoxylin and eosin), and CD31-immunohistochemistry $(\mathbf{I}-\mathbf{L} ; \times 20)$, the corneas of mice deficient in TSP-1 (A, E, I), -2 (B, F, $\mathbf{J})$, and TSP-1 and -2 (C, G, K) did not show evidence of spontaneous corneal angiogenesis (D, H, L: wild-type control). Magnification: $(\mathbf{E}-\mathbf{H}) \times 400$; (I-L) $\times 20$.

\section{Influence of Deficiency of TSP-1, -2, or Both TSP-1 and -2 on Iris Vascular Density}

The normal iris contains a rich vascular bed within its stroma. To determine whether a lack of the antiangiogenic factors TSP-1 or -2 (or both) influences the development of this vascularization process, we compared iris stromal vascular density between $\mathrm{TSP}^{-1-}$ mice and wild-type control animals at ages 2 , 3 , and 6 months, using a morphometric analysis. The density of iris stromal vessels was moderately but significantly increased in TSP-1 $^{-/-}$mice $(13.6 \pm 3.5$ vessel cross-sections/section) compared with wild-type control mice $(10.3 \pm 3.1 ; P<0.01)$, and this difference was even greater in TSP- $2^{-1-}$ mice $(19 \pm$ 4.9 vessel cross-sections/section) compared with wild-type control mice $(10.3 \pm 3.1 ; P<0.0001 ;$ Fig. 4$)$. The same was true for TSP-double knockout animals $(17.7 \pm 3)$ compared with wild-type control mice $(10.3 \pm 3.1 ; P<0.0001)$. TSP$2^{-1-}$ mice had a significantly higher iris vascular density than TSP- $1^{-/-}$mice $(P<0.001)$. There was no significant difference between TSP- $2^{-I^{-}}$and $-1,2^{-I^{-}}$mice $(P=0.28)$. There was no significant difference between the iris vessel counts across ages 2, 3, or 6 months. Therefore, all results were pooled for statistical analysis. No vessels were observed in front of the anterior iris stromal surface (i.e., no rubeotic vessels). These findings indicate that developmental angiogenesis in the iris is less redundantly regulated than in the cornea and is indeed regulated by TSP-1 and -2, because deficits in TSP-1, -2, or both permitted a significant expansion of iris stromal vascularity beyond that in wild-type mice.

\section{Influence of TSP-1, -2, or Both TSP-1 and -2 on Induced Corneal Angiogenesis}

When infected or traumatized, such as by placement of sutures in the central region, the cornea responds by acquiring newly generated blood vessels as outgrowths from the limbus. To determine whether deficiencies in either TSP-1 and/or -2 are sufficient to enhance induced $\mathrm{CNV}$, sutures were placed in the central corneas of eyes of $\mathrm{TSP}^{-/-}$and wild-type mice. Seven days later the corneas were excised, and the areas occupied by CD $31^{2+} /$ LYVE$^{-1}{ }^{-}$blood vessels ${ }^{3}$ were compared (Fig. 5). The hemevascularized areas of the corneas were significantly greater (Fig. 5A) in TSP-1 $1^{-1-}$ mice $(49.1 \% \pm 14.9 \%)$ than in wild-type control mice $(25.6 \% \pm 16.6 \% ; P<0.0001)$, (B) in TSP- $2^{-\prime-}$ mice $(35.7 \% \pm 18.6 \%)$ than in wild-type control mice (25.6\% $16.6 \% ; P=0.049)$, and $(C)$ in TSP-1, $2^{-/-}$mice $(46.8 \%$ $\pm 15.8 \%)$ than in wild-type control mice $(25.6 \% \pm 16.6 \% ; P<$ $0.0001)$. The hemevascularized area was significantly greater in TSP-1 ${ }^{-1-}$ mice and TSP- $1,2^{-{ }^{-}}$mice than in TSP-2 $2^{-1-}$ mice $(P<0.01)$. There was no significant difference between TSP$1^{-I^{-}}$mice and TSP $-1,2^{-I^{-}}$mice $(P=0.75)$. Together, these results indicate that TSP-1, more so than TSP-2 plays an important, perhaps dominant, role in suppressing angiogenesis in response to an inflammatory insult to the cornea.

\section{Discussion}

The cornea is one of the few avascular tissues present in the adult body, and the only one that can become vascularized secondarily, a process called corneal neovascularization (CNV). Because CNV compromises corneal transparency, which is essential for visual acuity and strongly selected for during evolution, it seems appropriate that control of corneal avascularity during development and adult life should be redundantly organized. It is also likely that the balance between pro- and antiangiogenic factors in the normal cornea is shifted constitutively toward inhibitors. Recent interest has focused on these natural inhibitors of angiogenesis, because they may be of therapeutic use in diseases leading to $\mathrm{CNV}$ and subsequent blindness. $^{21,24}$

Previous reports on the effects on developmental and postnatal angiogenesis of a deficit of a single antiangiogenic factor did not reveal spontaneous $\mathrm{CNV}$ in mice (Fig. 5A) lacking angiostatin resulting from a knockout of its precursor plasminogen, ${ }^{25}$ (B) lacking endostatin secondary to a knockout of its precursor, collagen type XVIII, ${ }^{26}$ and (C) missing TIMP, ${ }^{27}$ al- 


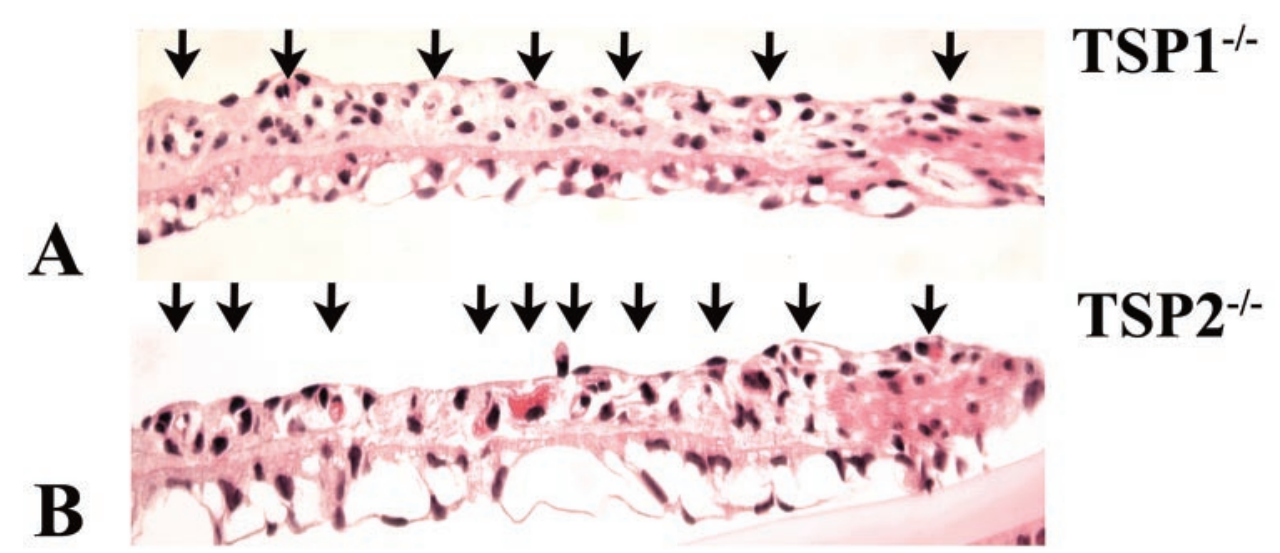

FigURE 4. Lack of TSP-1, -2, or both -1 and -2 caused increased iris vascular density. Increased vascularity of the anterior iris stroma can be observed in TSP-1 ${ }^{-1-}$ (A) $,-2^{-/-},(\mathbf{B})$ and in -1 and -2 double-deficient mice (C) compared with wild-type mice (D) arrows mark vessel cross sections in the iris stroma; hematoxylin eosin). (E) Significantly increased developmental iris vascular density in TSP-1 ${ }^{-\prime-}\left({ }^{* *} P<0.01\right)$, TSP-2 ${ }^{-/-}$ $\left({ }^{* * *} P<0.0001\right)$, and TSP- $1,2^{-1-}$ mice $\left({ }^{* * *} P<0.0001\right)$ compared with the wild-type control. Note that the absence of TSP- $2^{-\prime-}$ caused the maximum increase in iris vascular density, which was significantly greater than in TSP-1 ${ }^{-1-}$ mice $(P<0.001)$. Original magnification: $(\mathbf{A}-\mathbf{D}) \times 400$.
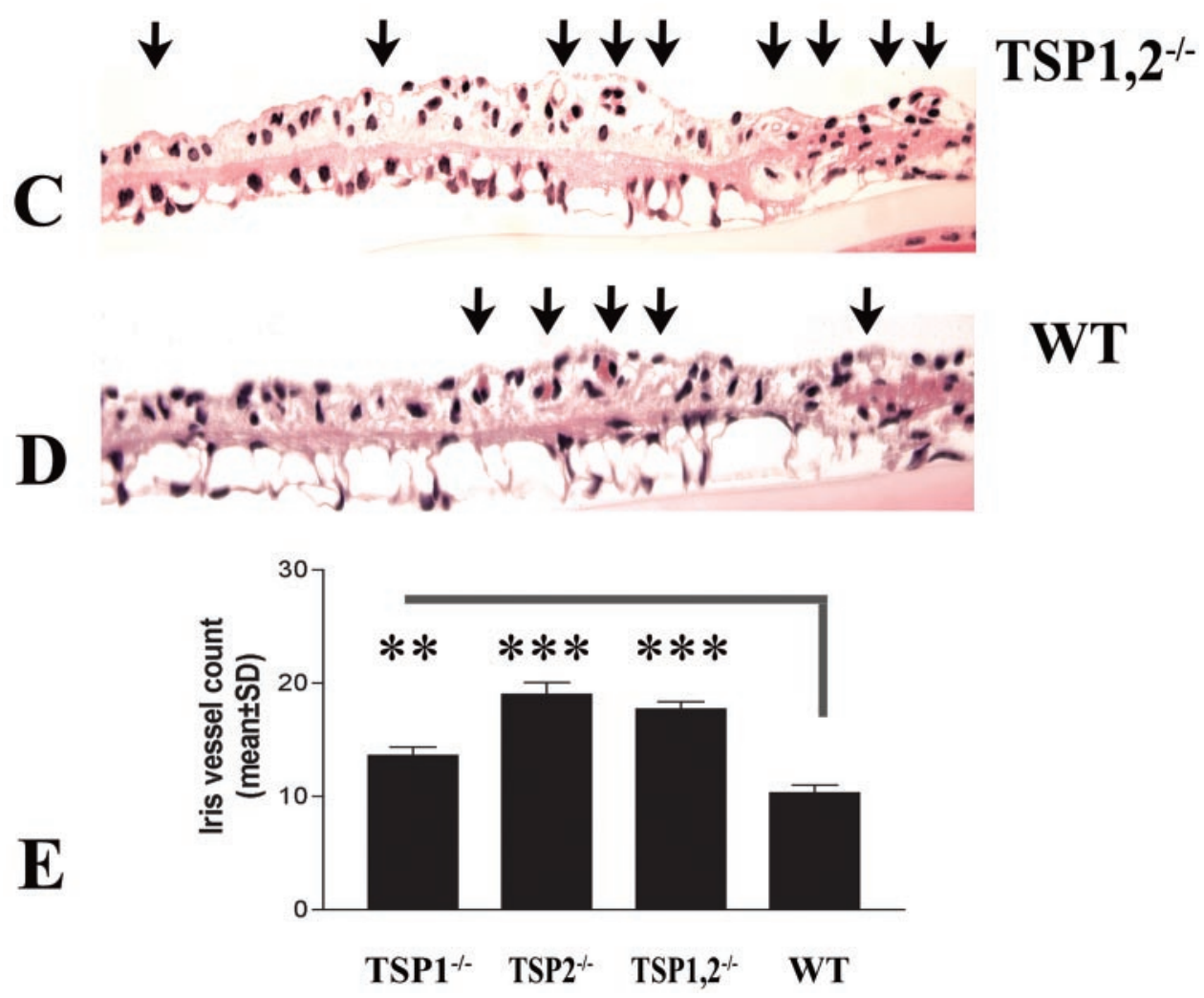

though it is not clear whether this was specifically addressed in these studies. ${ }^{25-27}$ In none of these studies was the effect of the absence of antiangiogenic factors on induced $\mathrm{CNV}$ examined. Our results support the view that no single factor maintains corneal avascularity during development. We provide in vivo evidence that removal of one or even two important endogenous corneal antiangiogenic factors (i.e., TSP-1, -2 , or both) does not result in spontaneous CNV. Together, the findings strongly support the hypothesis that corneal avascularity is regulated by multiple antiangiogenic proteins during development and postnatally.

By contrast, regulation of angiogenesis after trauma to the corneal surface with central sutures appears to be much less redundant. We demonstrate in this study that a significant increase in angiogenesis (i.e., active outgrowth of blood vessels into the normally avascular cornea) occurs in sutured corneas of TSP-1 $1^{-1-},-2^{-/-}$, and $-1,2^{-1-}$ mice compared with their background strain. These findings establish TSP-1 and -2 as important inhibitors of inflammation-induced $\mathrm{CNV}$ in vivo. Because the angiogenic phenotype of the TSP-1 and - 2 double- deficient mice equaled that of the TSP-1 ${ }^{-1-}$ mice and both had significantly greater angiogenic responses of induced corneal angiogenesis than the response of TSP- $2^{-/-}$mice, we conclude that TSP-1 is more important than TSP-2 in inhibiting inflammatory (corneal) angiogenesis. However, the opposite is true for noninflammatory, developmental iris angiogenesis, because iris vessel counts in TSP-2 $2^{-\prime-}$ mice were significantly higher than in TSP-1 ${ }^{-1-}$ mice, suggesting that TSP-2 is more important in regulating developmental intraocular angiogenesis than TSP-1.

In this context, the molecular relationships of TSPs and TGF $\beta$ must be considered. TSP- 1 has a unique peptide sequence that binds latent TGF $\beta$, thereby converting it into active $\operatorname{TGF} \beta .^{30,31}$ This is pertinent because it has previously been shown that tight regulation of TGF $\beta$ expression is necessary for maintaining corneal avascularity ${ }^{4}$ : TGF $\beta 1$-overexpressing mice display a vascularized and disorganized corneal phenotype. ${ }^{4}$ Unlike TSP-1, TSP-2 lacks the capacity to activate latent TGF $\beta 1$ (yet to be shown in the eye), ${ }^{12}$ and because TSP-2 has a strong effect on developmental iris angiogenesis and a 

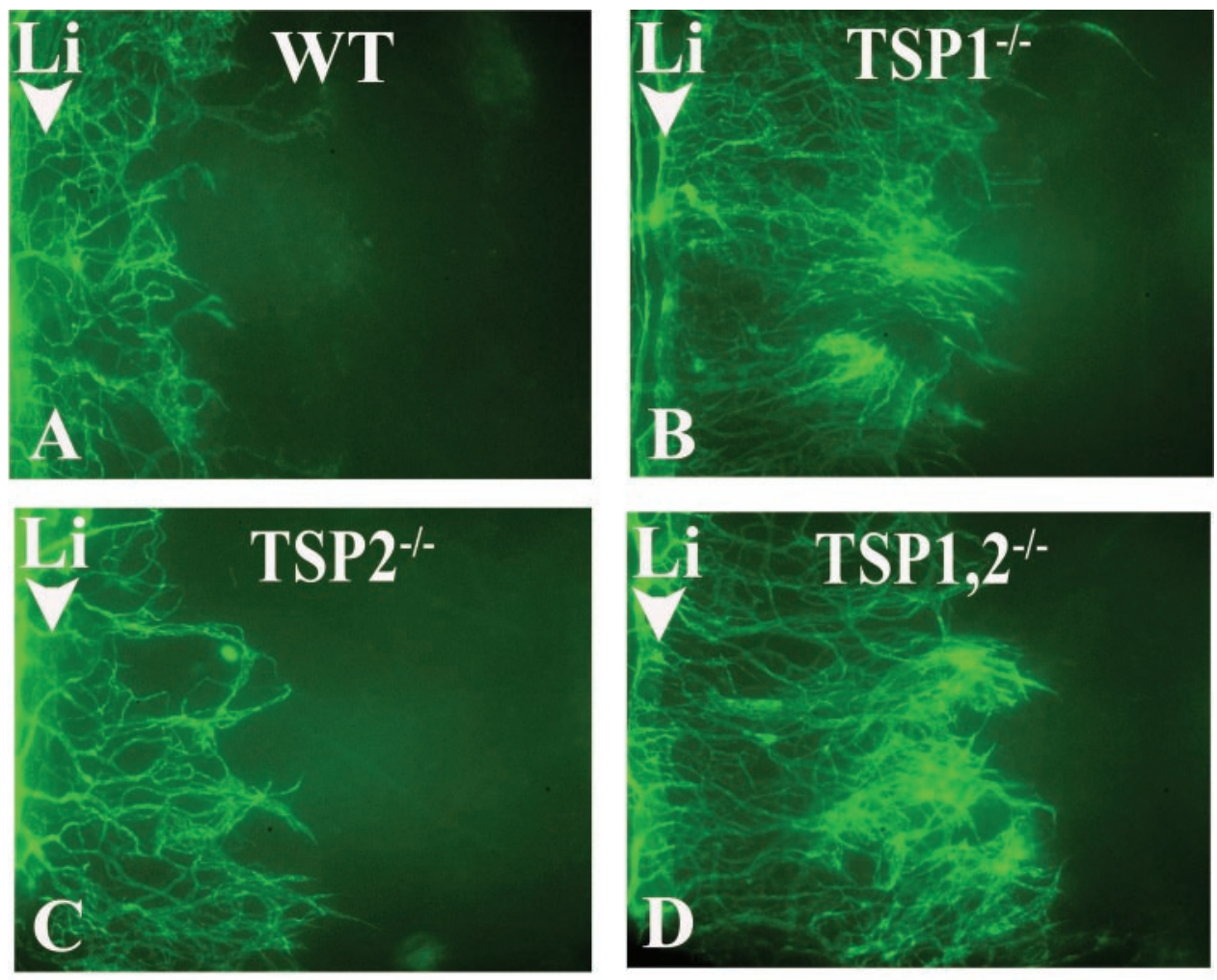

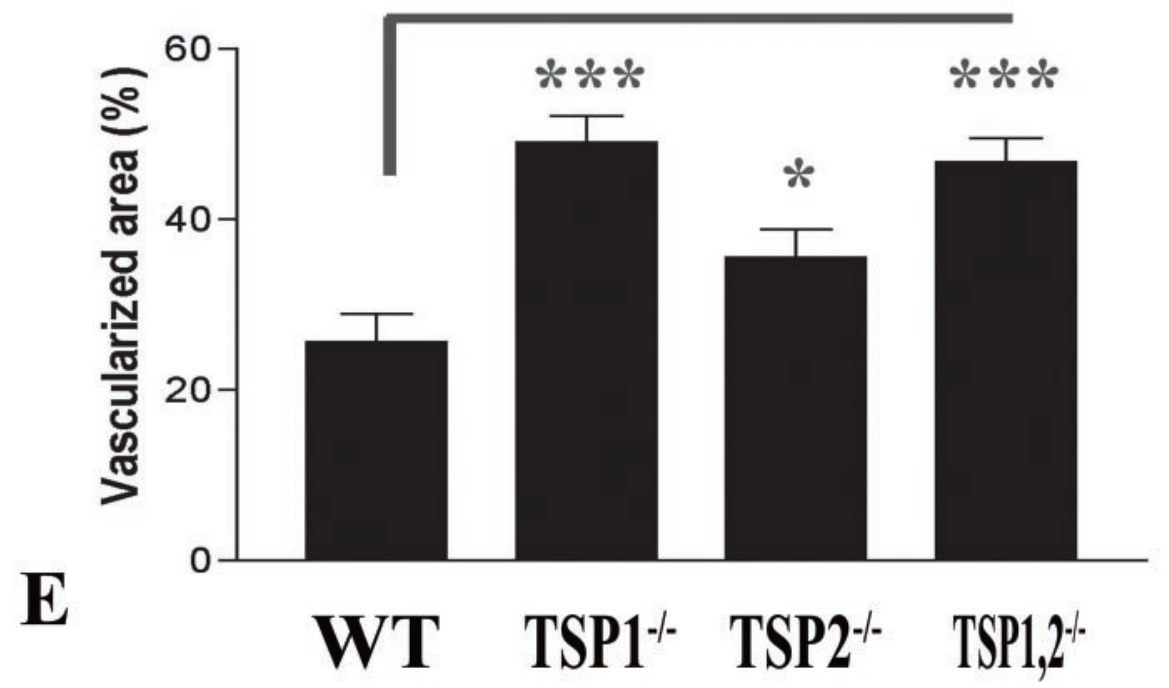

FIGURE 5. Both TSP-1 and -2 have an antiangiogenic effect in vivo in induced corneal neovascularization (mouse model of inflammatory, suture-induced, corneal neovascularization). Compared with wild-type control mice (A), TSP-1 ${ }^{-/-}\left(\mathbf{B} ;{ }^{* * *} P<<\right.$ $0.001)$, TSP$^{-1-}\left(\mathrm{C}^{-*}{ }^{*} P<0.05\right)$, and TSP-1, ${ }^{-1-}$ mice $\left(\mathbf{D} ;{ }^{* * *} P<0.001\right)$ displayed significantly increased corneal angiogenesis 1 week after suture placement, as shown by the CD31positive areas in the corneal flatmounts ( $\mathrm{Li}$, limbal vascular arcade). (E) The induced angiogenic response was significantly greater in TSP-1 $1^{-1-}$ and $-1,2^{-/-}$mice than in TSP- $2^{-1-}$ mice $(P<0.01)$. Original magnification: $(\mathbf{A}-\mathbf{D}) \times 100$.

weak effect on induced $\mathrm{CNV}$, we conclude that this regulation is achieved by a TGF $\beta$-independent pathway. ${ }^{23}$

Our findings further indicate that TSPs have a more important effect on developmental and postnatal angiogenesis in the iris than in the cornea. Iris tissues from unmanipulated eyes of TSP-1 ${ }^{-1-},-2^{-1-}$ and $-1,2^{-1-}$ mice displayed significantly increased stromal vascular density in comparison to wild-type mice. This finding is the first evidence that TSP-1 and -2 are involved in regulating developmental-postnatal angiogenesis and in controlling the degree of vascularity of ocular tissues. In line with this role of TSP-1 and -2 in developmental ocular angiogenesis, TSP-1 and -2 mRNA expression was detected in the developing murine eye from postconception day 13 (TSP-1) and day 16 (TSP-2). ${ }^{30}$ The increase of iris vascular density in $\mathrm{TSP}^{-1-}$ mice may be due to reduced Fas-FasLmediated apoptosis of new blood vessels in the iris, because it is known that this is one mechanism by which TSP-1 inhibits angiogenesis, and because Fas- and FasL-deficient mice display increased vascular density of certain tissues, such as the retina. ${ }^{31}$ A role for TSP in developmental angiogenesis is not limited to eye tissues. TSP-2 deficiency has previously been shown to be associated with increased vascular density in the skin, thymus, and adipose tissue, but not in the CNS. ${ }^{19}$ TSP-1 deficiency has also been linked to increased developmental angiogenesis in the $\operatorname{skin}^{29}$ and to elevated intraocular vessel counts, yet it remains unclear which vessels were actually counted in the latter study. ${ }^{32}$

TSP-1 and -2 are important inhibitors of angiogenesis (for review, see Refs. 11-13), but published reports of their roles in inflammatory CNV have been controversial. Whereas both TSP$1^{16,33}$ and $-2^{15}$ have been shown to inhibit bFGF-induced CNV in the corneal micropocket assay (in mice or rabbit, respec- 
tively), BenEzra et al. ${ }^{34}$ found that TSP-1 enhanced the in vivo angiogenic process induced by bFGF or lipopolysaccharide (LPS) in the cornea. They attributed this enhancement to the known chemotactic effect of TSP-1 on polymorphonuclear cells and macrophages. ${ }^{34}$ Another explanation may be that binding of TSP-1 to CD47, at higher concentrations, also induces endothelial cell migration (for review, see Ref. 13).

We are intrigued that TSPs have a significant effect on inflammatory, but not on postnatal developmental CNV. We speculate that during development, other inhibitors compensate for the absence of TSP-1 and/or - 2 in the knockout mice, and that these inhibitors are sufficient to maintain angiostasis in postnatal life, as long as trauma to the ocular surface is trivial. If, however, a postnatal angiogenic stimulus exceeds the threshold of protection provided by these other inhibitors, the absence of TSP-1, more so than TSP-2, permits induced $\mathrm{CNV}$ to proceed. This suggests a constitutive system of regulation that can control angiogenic stimuli up to a certain level of intensity, after which it fails. If corneal avascularity is to be maintained beyond this threshold, other factors or enhanced expression of endogenous inhibitors must intervene. We further speculate that upregulation of TSPs by inflammatory angiogenic stimuli helps to control CNV beyond this threshold. In favor of this view is the report that TSP- $2^{-1-}$ mice display prolonged and intensified inflammatory and angiogenic responses in the cutaneous delayed hypersensitivity model. ${ }^{35}$ Similarly, VEGF upregulates TSP-1 in the angiogenically stimulated retina. ${ }^{36}$ Because we have shown that the genes for TSP-1 and -2 are constitutively active in the normal cornea, it is reasonable to expect that inflammation in the cornea further upregulates their expression, thus enhancing the negative feedback loop for angiostasis. In fact, TSP-1 has been shown to be upregulated in response to corneal injury ${ }^{37}$ and it has recently been shown that keratocytes in the corneal stroma, in addition to TSP-1, can upregulate TSP-2 during a wound repair phenotype. ${ }^{38}$ The fact that mRNA expression of both antiangiogenic factors at rest was significantly higher in the cornea than in iris tissue suggests that the constitutive levels of antiangiogenic factors in the cornea far exceeds their levels in vascularized ocular tissues. The only other extraocular avascular tissue, cartilage, correspondingly shows a strong immunoreactivity for TSP-2 both during development and in the adult. ${ }^{39}$ The concept advanced here of a redundantly organized corneal angiogenic privilege with thresholds of response offers an explanation for the clinical observation that angiogenesis does not usually emerge after successful refractive surgery. ${ }^{1}$

\section{Acknowledgments}

The authors thank Jacqueline Doherty, PhD, for general support, Jian Gu for help with histologic sectioning, and Marie Ortega and Stephanie Carol for help with breeding of TSP-deficient mice.

\section{References}

1. Chang JH, Gabison EE, Kato T, Azar DT. Corneal neovascularization. Curr Opin Ophthalmol. 2001;12:242-249.

2. Streilein JW. Regional immunity and ocular immune privilege. Chem Immunol. 1999;73:11-38.

3. Cursiefen C, Schlötzer-Schrehardt U, Küchle M, et al. Lymphatic vessels in vascularized human corneas: immunohistochemical investigation using LYVE-1 and podoplanin. Invest Ophthalmol Vis Sci. 2002; 43:2127-2135.

4. Flugel-Koch C, Ohlmann A, Piatigorsky J, Tamm ER. Disruption of anterior segment development by TGF-beta1 overexpression in the eyes of transgenic mice. Dev Dyn. 2002;225:111-255.

5. Fannon M, Forsten-Williams K, Dowd CJ, Freedman DA, Folkman $\mathrm{J}$, Nugent MA. Binding inhibition of angiogenic factors by heparan sulfate proteoglycans in aqueous humor: potential mechanism for maintenance of an avascular environment. FASEB J. 2003;17:902904.

6. Hiscott P, Seitz B, Schlötzer-Schrehardt U, Naumann GO. Immunolocalisation of thrombospondin 1 in human, bovine and rabbit cornea. Cell Tissue Res. 1997;289:307-310.

7. Ogata N, Wada M, Otsuji T, Jo N, Tombran-Tink J, Matsumura M. Expression of pigment epithelium-derived factor in normal adult rat eye and experimental choroidal neovascularization. Invest $O p h$ thalmol Vis Sci. 2002;43:1168-1175.

8. Opbroek A, Kenney MC, Brown D. Characterization of a human corneal metalloproteinase inhibitor (TIMP-1). Curr Eye Res. 1993; 12:877-883.

9. Lin HC, Chang JH, Jain S, et al. Matrilysin cleavage of corneal collagen type XVIII NC1 domain and generation of a 28 -kDa fragment. Invest Ophthalmol Vis Sci. 2001;42:2517-2524.

10. Liu JJ, Wilson SE. Characterization of human and mouse angiopoietin-like factor CDT6 promoters. Invest Ophthalmol Vis Sci. 2001; 42:2776-8312.

11. Lawler J. Thrombospondin-1 as an endogenous inhibitor of angiogenesis and tumor growth. J Cell Mol Med. 2002;6:1-12.

12. Lawler J. The functions of thrombospondin-1 and-2. Curr Opin Cell Biol. 2000;12:634-640.

13. Armstrong LC, Bornstein P. Thrombospondin 1 and 2 function as inhibitors of angiogenesis. Matrix Biol. 2003;22:63-71.

14. Jimenez B, Volpert OV, Crawford SE, Febbraio M, Silverstein RL, Bouck N. Signals leading to apoptosis-dependent inhibition of neovascularization by thrombospondin-1. Nat Med. 2000;6:4148.

15. Volpert OV, Tolsma SS, Pellerin S, et al. Inhibition of angiogenesis by thrombospondin-2. Biochem Biophys Res Commun. 1995;217: 326-332.

16. Simantov R, Febbraio M, Crombie R, Asch AS, Nachman RL, Silverstein RL. Histidine-rich glycoprotein inhibits the antiangiogenic effect of thrombospondin-1. J Clin Invest. 2001;107:45-52.

17. Lawler J, Sunday M, Thibert V, et al. Thrombospondin-1 is required for normal murine pulmonary homeostasis and its absence causes pneumonia. J Clin Invest. 1998;101:982-992.

18. Agah A, Kyriakides T, Lawler J, Bornstein P. The lack of thrombospondin-1 (TSP1) dictates the course of wound healing in double-TSP1/TSP2-null mice. Am J Pathol. 2002;161:831-839.

19. Kyriakides TR, Zhu YH, Smith LT, et al. Mice that lack thrombospondin 2 display connective tissue abnormalities that are associated with disordered collagen fibrillogenesis, an increased vascular density, and a bleeding diathesis. J Cell Biol. 1998;140:419430.

20. Streilein JW, Bradley D, Sano Y, Sonoda Y. Immunosuppressive properties of tissues obtained from eyes with experimentally manipulated corneas. Invest Ophthalmol Vis Sci. 1996;37:413-424.

21. Ambati B, Joussen AM, Ambati J, et al. Angiostatin inhibits and regresses corneal neovascularization. Arch Ophthalmol. 2002;120: 1063-1068.

22. Banerji S, Ni J, Wang SX, et al. LYVE-1, a new homologue of the CD44 glycoprotein, is a lymph-specific receptor for hyaluronan. J Cell Biol. 1999;144:789-801.

23. Masli S, Turpie B, Hecker KH, Streilein JW. Expression of thrombospondin in TGFbeta-treated APCs and its relevance to their immune deviation-promoting properties. J Immunol. 2002;168: 2264-2273.

24. Carmeliet P, Jain RK. Angiogenesis in cancer and other diseases. Nature. 2000;407:249-257.

25. Bugge TH, Flick MJ, Daugherty CC, Degen JL. Plasminogen deficiency causes severe thrombosis but is compatible with development and reproduction. Genes. Dev. 1995;9:794-807.

26. Fukai N, Eklund L, Marneros AG, et al. Lack of collagen XVIII/ endostatin results in eye abnormalities. EMBO J. 2002;21:15351544.

27. Soloway PD, Alexander CM, Werb Z, Jaenisch R. Targeted mutagenesis of Timp-1 reveals that lung tumor invasion is influenced by Timp-1 genotype of the tumor but not by that of the host. Oncogene. 1996;13:2307-2314.

28. Schultz-Cherry S, Ribeiro S, Gentry L, Murphy-Ullrich JE. Thrombospondin binds and activates the small and large forms of latent 
transforming growth factor-beta in a chemically defined system. J Biol Chem. 1994;269:26775-26782.

29. Crawford SE, Stellmach V, Murphy-Ullrich JE, et al. Thrombospondin-1 is a major activator of TGF-beta1 in vivo. Cell. 1998; 93:1159-1170.

30. Iruela-Arispe L, Liska D, Sage H, Bornstein P. Differential expression of thrombospondin 1,2 , and 3 during murine development. Dev Dyn. 1993;197:40-56.

31. Volpert $\mathrm{O}$, Zaichuk $\mathrm{T}$, Zhou W, et al. Inducer-stimulated Fas targets activated endothelium for destruction by anti-angiogenic thrombospondin-1 and pigment epithelium-derived factor. Nat Med. 2002;8:349-357.

32. Stellmach V, Volpert OV, Crawford SE, Lawler J, Hynes RO, Bouck $\mathrm{N}$. Tumour suppressor genes and angiogenesis: the role of TP53 in fibroblasts. Eur J Cancer. 1996;32:2394-2400.

33. Jimenez B, Volpert OV, Reiher F, et al. c-Jun N-terminal kinase activation is required for the inhibition of neovascularization by thrombospondin-1. Oncogene. 2001;20:3443-3448.

34. BenEzra D, Griffin BW, Maftzir G, Aharonov O. Thrombospondin and in vivo angiogenesis induced by basic fibroblast growth factor or lipopolysaccharide. Invest Ophthalmol Vis Sci. 1993;34:36013608.

35. Lange-Asschenfeldt $B$, Weninger $W$, Velasco $P$, et al. Increased and prolonged inflammation and angiogenesis in delayed-type hypersensitivity reactions elicited in the skin of thrombospondin-2-deficient mice. Blood. 2002;99:538-545.

36. Suzuma K, Takagi H, Otani A, Oh H, Honda Y. Expression of thrombospondin-1 in ischemia-induced retinal neovascularization. Am J Pathol. 1999;154:343-354.

37. Cao Z, Wu HK, Bruce A, Wollenberg K, Panjwani N. Detection of differentially expressed genes in healing mouse corneas, using cDNA microarrays. Invest Ophthalmol Vis Sci. 2002;43:28972904.

38. Armstrong DJ, Hiscott P, Batterbury M, Kaye S. Corneal stromal cells (keratocytes) express thrombospondins 2 and 3 in wound repair phenotype. Int J Biochem Cell Biol. 2002;34:588-593.

39. Kyriakides TR, Zhu YH, Yang Z, Bornstein P. The distribution of the matricellular protein thrombospondin 2 in tissues of embryonic and adult mice. J Histochem Cytochem. 1998;46:1007-1015. 